\title{
Prevention, identification, and treatment of perioperative spinal cord injury
}

\author{
Henry Ahn, M.D., F.R.C.S.C., ${ }^{1}$ And Michael G. Fehlings, M.D., Ph.D., F.R.C.S.C. ${ }^{2}$ \\ Divisions of ${ }^{1}$ Orthopaedic Surgery and ${ }^{2}$ Neurosurgery, University of Toronto Spine Program, Toronto, \\ Canada
}

Object. In this report, the authors suggest evidence-based approaches to minimize the chance of perioperative spinal cord injury (POSCI) and optimize outcome in the event of a POSCI.

Methods. A systematic review of the basic science and clinical literature is presented.

Results. Authors of clinical studies have assessed intraoperative monitoring to minimize the chance of POSCI. Furthermore, preoperative factors and intraoperative issues that place patients at increased risk of POSCI have been identified, including developmental stenosis, ankylosing spondylitis, preexisting myelopathy, and severe deformity with spinal cord compromise. However, no studies have assessed methods to optimize outcomes specifically after POSCIs. There are a number of studies focussed on the pathophysiology of SCI and the minimization of secondary damage. These basic science and clinical studies are reviewed, and treatment options outlined in this article.

Conclusions. There are a number of treatment options, including maintenance of mean arterial blood pressure > $80 \mathrm{~mm} \mathrm{Hg}$, starting methylprednisolone treatment preoperatively, and multimodality monitoring to help prevent POSCI occurrence, minimize secondary damage, and potentially improve the clinical outcome of after a POSCI. Further prospective cohort studies are needed to delineate incidence rate, current practice patterns for preventing injury and minimizing the clinical consequences of POSCI, factors that may increase the risk of POSCI, and determinants of clinical outcome in the event of a POSCI. (DOI: 10.3171/FOC.2008.25.11.E15)

KeY Words • complication • review • spinal cord injury

$\mathrm{P}$ ERIOPERATIVE SCI is one of the most feared complications of spine surgery, potentially resulting in a devastating and debilitating outcome for the patient and tremendous stress for the surgeon. Fortunately, the incidence of POSCI is relatively uncommon with an estimated incidence varying from 0 to $3 \%$, depending on the pathological entity treated, the spinal level, and surgical approach. ${ }^{25,28}$ Perioperative SCI involves a direct or indirect physiological insult to the spinal cord during immediate preparation for surgery, intraoperatively, or immediately postoperatively. This physiological insult leads to neuronal/axonal dysfunction or disruption, and consequently to motor, sensory, and/or autonomic impairment. Injury to the spinal cord may be complete or incomplete, and can result in temporary or permanent impairment. Numerous trials of pharmacological agents for traumatic

\footnotetext{
Abbreviations used in this paper: $\mathrm{CSF}=$ cerebrospinal fluid; MABP $=$ mean arterial blood pressure; $\mathrm{MEP}=$ motor evoked potential; MPSS = methylprednisolone sodium succinate; NASCIS = National Acute Spinal Cord Injury Study; OPLL = ossification of the posterior longitudinal ligament; $\mathrm{POSCI}=$ perioperative spinal cord injury; $\mathrm{SCI}=$ spinal cord injury; SSEP = somatosensory evoked potentials.
}

SCI have been performed, with some trials showing a potential benefit: ${ }^{7-11,30,31,65}$ however, no reviews exist in the literature concerning the causes and management of POSCIs. The lack of a formal protocol for management of POSCI is the impetus for this paper, which will review the pathophysiology and causes of POSCI, and then propose evidence-based recommendations for the prevention of and treatment of POSCI based on a systematic review of basic science and clinical studies.

\section{Methods}

Searches were performed on Medline (1966 to June 2008), Embase, and the Cochrane Collaboration. Hand searches were also performed in the European Spine Journal, Spine, and Journal of Neurosurgery: Spine, along with bibliography searches of pertinent studies. Search strategy for Medline were: "exp Spinal Cord Injuries/" and "Intraoperative Complications/ or Postoperative Complications/," limited to the English language. Each of these searches produced 13185 and 94174 articles, respectively. Combining the searches resulted in 493 articles, and review of the articles and abstracts lead to 84 relevant articles. 


\section{H. Ahn and M. G. Fehlings}

TABLE 1. Outline of treatment options minimizing the incidence of a POSCl

\begin{tabular}{l}
\hline Options \\
1. Maintain MABP > $80 \mathrm{~mm} \mathrm{Hg}$ including during induction \\
2. Start MPSS in the holding area using NASCIS II dosing and sched- \\
uling \\
3. Maintain spinal control/precautions \\
4. Use adequate lighting, magnification, and assistance \\
5. Multimodality intraoperative neuromonitoring with SSEP/MEP/EMG \\
6. Careful application of distractive forces and recognition if applied, \\
that this can cause a stretch injury/ischemic injury to the spinal cord \\
7. Careful decompression with appropriate instrumentation to avoid \\
trauma to neural structures
\end{tabular}

Articles were included if they discussed methods to prevent the occurrence of or minimize the effects of a POSCI, the pathophysiology of SCIs, or methods to minimize the effects of secondary damage after SCI. Perioperative SCI encompasses SCI or clinical worsening of SCI just prior to, during, and after surgery. Articles included both basic science and clinical studies.

We present an overview of the pathophysiology of SCI, presurgical causes of SCI, intraoperative causes of SCI in the cervical and thoracic spine, postoperative causes of SCI, and long-term management of POSCIs. Following the overview are 2 case examples in which recommendations to prevent a POSCI were used (Table 1); in the second case recommendations for the treatment of perioperative spinal cord complications once they have occurred are discussed (Table 2). Evidentiary tables are provided that summarize both the basic science and clinical literature (Tables 3-5).

\section{Results}

\section{Pathophysiology of SCI}

Spinal cord injury is the result of a 2-step process that has both primary and secondary mechanisms. 69,79 The primary mechanism involves the initial injury, which may include compression, impaction, laceration, shearing, distraction, or ischemia. These mechanisms may occur at any point from the time of surgical planning, to the time of anesthesia, to intraoperatively, and in the

\section{TABLE 2. Outline of treatment options minimizing the effects of a $\mathrm{POSCl}$ once it has occurred}

\begin{tabular}{l}
\hline Options \\
1. Prompt recognition of SCI \\
2. If possible, prompt reversal of offending cause of $\mathrm{SCl}$ \\
3. Maintain MABP $>80 \mathrm{~mm} \mathrm{Hg}$ and correct hematocrit \\
4. Start MPSS in the holding area using NASCIS II dosing and sched- \\
uling \\
5. Stabilize the spinal region if it is unstable \\
6. HIGHLY CONTROVERSIAL: systemic cooling and CSF drainage \\
\hline
\end{tabular}

TABLE 3: Summary of basic science and clinical papers reviewed for the pathophysiology of acute $\mathrm{SCl}$ and presurgical causes and preoperative management of acute SCls

\begin{tabular}{|c|c|c|}
\hline Authors \& Year & $\begin{array}{l}\text { Data } \\
\text { Class }\end{array}$ & Study Type \\
\hline Kobrine et al., 1976 & & basic science \\
\hline Rydevik \& Lundborg, 1977 & & basic science \\
\hline Kobrine et al., 1979 & & basic science \\
\hline Senter \& Venes, 1979 & & basic science \\
\hline Tew \& Mayfield, 1980 & IV & nonsystematic review \\
\hline Young et al., 1980 & & basic science \\
\hline Demopoulos et al., 1982 & & basic science \\
\hline Dahlin et al., 1984 & & basic science \\
\hline Epstein et al., 1984 & IV & case series \\
\hline Bracken et al., 1985 & I & randomized control trial (RCT) \\
\hline Fehlings et al., 1989 & & basic science \\
\hline Bracken et al., 1990 & I & $\mathrm{RCT}$ \\
\hline Tator \& Fehlings, 1991 & & basic science \\
\hline Geisler et al., 1991 & I & $\mathrm{RCT}$ \\
\hline Laroche et al., 1992 & III & case control \\
\hline Bracken et al., 1992 & I & $\mathrm{RCT}$ \\
\hline Hall, 1993 & & basic science \\
\hline Naso et al., 1995 & & basic science \\
\hline Vale et al., 1997 & II & prospective study \\
\hline Gerndt et al., 1997 & III & case-control \\
\hline Petitjean et al., 1998 & 1 & $\mathrm{RCT}$ \\
\hline Gisselsson et al., 1999 & & basic science \\
\hline Sauerland et al., 2000 & I & systematic review of RCTs \\
\hline Sekhon \& Fehlings, 2001 & III & $\begin{array}{l}\text { review of epidemiology and } \\
\text { basic science }\end{array}$ \\
\hline Bracken, 2001 & 1 & $\begin{array}{l}\text { systematic review of Level I } \\
\text { evidence }\end{array}$ \\
\hline Nakao et al., 2001 & & basic science \\
\hline Geisler et al., 2001 & I & RCT \\
\hline Molano et al., 2002 & III & case-control \\
\hline Lee et al., 2007 & III & case-control \\
\hline Suberviola et al., 2008 & III & case-control \\
\hline
\end{tabular}

immediate postoperative period. The secondary cascade includes a complex series of biochemical and cellular processes, initiated by the primary processes, which potentially cause further cell damage and death. This cascade of events includes: 1) vascular changes with loss of autoregulation, decreased blood flow, and hemorrhage; 2) ionic derangements, including elevated intracellular calcium, sodium, and potassium; 3) neurotransmitter accumulation, including glutamate and catecholamines; 4) free radical production and lipid peroxidation; 5) edema; 6) inflammation; and 7) apoptosis. Once complete disruption of the neural elements has occurred, the possibility of recovery is minimal, regardless of treatment. As a result, the best possible method for minimizing the effects of POSCI is through prevention and understanding the various potential causes from the time of surgical planning, 
TABLE 4: Summary of basic science and clinical papers reviewed for the surgical causes and intraoperative management of acute SCls

\begin{tabular}{|c|c|c|}
\hline Authors \& Year & $\begin{array}{l}\text { Data } \\
\text { Class }\end{array}$ & Study Type \\
\hline Dommisse, 1974 & & basic science \\
\hline MacEwan, 1975 & III & survey \\
\hline Flynn, 1982 & IV & case series \\
\hline Emery et al., 1988 & IV & case series \\
\hline Fessler et al., 1988 & IV & case series \\
\hline Bertalanffy \& Eggert, 1989 & IV & case series \\
\hline Graham et al., 1989 & IV & case series \\
\hline Tator \& Fehlings, 1991 & IV & case series \\
\hline Fielding, 1992 & IV & case series \\
\hline Davison et al., 1994 & IV & case series \\
\hline Faciszewski et al., 1995 & IV & case series \\
\hline Graham et al., 1996 & II & prospective cohort \\
\hline Winter, 1997 & V & nonsystematic review \\
\hline Hoppenfeld et al., 1997 & I & $\begin{array}{l}\text { prospective, diagnostic } \\
\text { testing }\end{array}$ \\
\hline Dickman \& Sonntag, 1998 & II & prospective cohort \\
\hline Albert et al., 1998 & & case series \\
\hline $\begin{array}{l}\text { Koscielniak-Nielsen et al., } \\
1998\end{array}$ & I & RCT \\
\hline Maliszewski et al., 1999 & & basic science \\
\hline Abumi et al., 2000 & IV & case series \\
\hline Haid et al., 2001 & IV & case series \\
\hline Harms \& Melcher, 2001 & IV & case series \\
\hline Suk et al., 2001 & IV & case series \\
\hline Tabayashi et al., 2002 & IV & case series \\
\hline Deen et al., 2003 & II & prospective cohort \\
\hline Husted et al., 2003 & & basic science \\
\hline Krassioukov et al., 2004 & II & $\begin{array}{l}\text { prospective, diagnostic } \\
\text { criteria development }\end{array}$ \\
\hline Gunnarsson et al., 2004 & II & retrospective cohort \\
\hline $\begin{array}{l}\text { Tabayashi \& Tabayashi, } \\
2005\end{array}$ & & review article \\
\hline Orchowski et al., 2005 & IV & case series \\
\hline Inoue et al., 2005 & II & prospective cohort \\
\hline Kwon et al., 2008 & ॥ & review article \\
\hline
\end{tabular}

to the implementation of anesthesia, to the operation and immediately afterwards. Moreover, because the secondary injury events after neurotrauma evolve over minutes to hours, early recognition of POSCI is critical so that appropriate treatment can be instituted with the hope of minimizing the secondary injury cascade.

\section{Presurgical Causes of POSCI}

Although not necessarily the cause of SCI, a delay in recognizing or an inappropriate delay in surgical treatment for acute compression of the cervical or thoracic spinal cord can lead to progression of SCI while awaiting
TABLE 4: Summary of basic science and clinical papers reviewed for postsurgical causes and postoperative management of acute SCls

\begin{tabular}{|c|c|c|}
\hline Authors \& Year & $\begin{array}{l}\text { Data } \\
\text { Class }\end{array}$ & Study Type \\
\hline Miyamoto et al., 1960 & IV & case series \\
\hline Griffiths et al., 1978 & & basic science \\
\hline Teplick \& Haskin, 1983 & IV & case series \\
\hline Woolsey, 1985 & IV & case series \\
\hline Bower et al., 1989 & & basic science \\
\hline Djukic et al., 1990 & V & review, nonsystematic \\
\hline Kotilainen et al., 1994 & $\|$ & prospective cohort \\
\hline Vandermeulen et al., 1994 & V & nonsystematic review \\
\hline Lawton et al., 1995 & IV & case series \\
\hline Baker et al., 1996 & IV & case series \\
\hline Weaver et al., 2001 & IV & case series \\
\hline Kou et al., 2002 & III & case-control \\
\hline Coselli et al., 2002 & I & RCT \\
\hline Acikbas et al., 2002 & IV & case series \\
\hline Uribe et al., 2003 & IV & case series \\
\hline Sorensen, 2003 & III & case-control \\
\hline Suri et al., 2003 & $\|$ & retrospective cohort \\
\hline Settepani et al., 2003 & IV & case series \\
\hline Huang et al., 2004 & & basic science \\
\hline Curry et al., 2005 & IV & case series \\
\hline Schade et al., 2005 & ॥ & prospective cohort \\
\hline
\end{tabular}

treatment, and minimize cord recovery after surgery. In vitro, cord recovery has been shown to be related to the duration and the force of compression. ${ }^{15,66}$ Timely recognition of the pathological entity, its extent, and expedited treatment of patients with incomplete SCIs provide an optimal chance of recovery.

Another potential presurgical cause of POSCI is hyperextension of the neck during intubation and positioning. The method of intubation is critical especially in patients with severely tight cervical canals such as those with congenital stenosis, diffuse idiopathic skeletal hyperostosis, OPLL, and also those with severe spondylosis of the lumbar spine, as there is a correlation with spondylosis of the cervical spine. ${ }^{24,54}$ Other patients at risk for SCI from intubation, or iatrogenic worsening of an already existing SCI, are those with potentially unstable cervical spines who have rheumatoid arthritis, Down syndrome, traumatic cervical spine injuries, and hypermobile transition zones between fused regions, such as in Klippel-Feil syndrome. In either group of patients, a careful fiberoptic endotracheal intubation without hyperextension of the neck is an important consideration to prevent SCI. ${ }^{81}$ Following intubation, positioning of the patient should be performed with careful control of the spine. Transfer of the patient after intubation should be performed safely and with enough assistance to ensure gentle atraumatic positioning of the spine.

Hypotension is another potential presurgical cause of POSCI, and can occur during or after the induction 
of anesthesia. Hypotension can lead to decreased cord perfusion and worsen an existing SCI, because the "cord at risk" cannot self-autoregulate. ${ }^{26,47,48,70,88}$ Maintaining hypotensive anesthesia to minimize blood loss is contraindicated in patients with preexisting SCIs or who are at high risk for intraoperative SCI. Vasopressors such as dopamine and levophed should be used at the start of induction to maintain the MABP $>80-85 \mathrm{~mm} \mathrm{Hg}$ in cases where the cord is already injured or at risk for further cord injury. ${ }^{83}$

\section{Surgical Causes of POSCI in the Cervical Spine}

In the anterior cervical spine, the risk of cord injury during anterior cervical discectomy is low, $0-0.3 \% .^{29,34}$ In cases of stenotic cervical spines with preexisting myelopathy, rates of SCI or worsening of preexisting myelopathies are higher, but remain low, 1-3\% when an anterior approach is used. ${ }^{5,23,27}$ Adequate lighting and visualization with magnification of the anterior spinal cord is important during decompression. In general, no pressure or manipulation of the cord should happen. During instrumentation, great care must be maintained to ensure that all drill bits, retraction pins, and screws have lengths shorter than the sagittal diameter of the vertebral body.

In a 5-year review, Graham ${ }^{37}$ revealed that the rate of SCI from a posterior approach was higher than when an anterior approach was used for decompression; the overall rate of neurological injury was 2.18 and $0.64 \%$, respectively. Posterior cervical instrumentation has also been shown to be safe and low risk. Lateral mass screw insertion has been shown to be reliable with minimal risk to the spinal cord because screws are directed away from the cord. ${ }^{18}$ Neurological injury with lateral mass screws are usually nerve root injuries, occurring at a rate of 1.3$1.8 \%{ }^{18,36}$ Pedicle screws placed at C-7 are also safe; Vaccaro et al. ${ }^{1,3}$ showed no occurrence of SCI when screws were placed in conjunction with a laminoforaminotomy. The use of transarticular screws at C1-2, although a technically demanding procedure, has been shown to be a safe method of fusion, with several authors demonstrating no occurrence of cord injury. ${ }^{20,40}$ The C-1 lateral mass/C-2 pars screw fixation technique is also a safe alternative in patients who cannot undergo transarticular screw fixation due to anatomical limitations such as a high riding vertebral artery or fixed subluxation of C-1 on C-2. Harms and Melcher ${ }^{42}$ showed that the technique can be performed without injury to the cord. For posterior instrumentation, sagittally reconstructed CT scans should be obtained preoperatively to assess the bone anatomy and the trajectories for cervical pedicle screws, to minimize the chance of cord or vertebral artery injury.

\section{Surgical Causes of POSCI in the Thoracic Spine}

The gray matter of the midthoracic spine from T-4 to $\mathrm{T}-9$ is considered to be a vascular watershed zone. ${ }^{22}$ Hypotension or hypovolemia should be avoided and the MABP should be maintained higher than $80-85 \mathrm{~mm} \mathrm{Hg}$. This may require the use of vasopressors such as dopamine starting prior to or at the time of anesthesia induction.
Intraoperative thoracic SCIs occur by a variety of different mechanisms during anterior approaches to the thoracic spine. Disruption of the radiculomedullary feeding arteries of the thoracic cord, including the artery of Adamkiewicz can lead to spinal cord infarction. ${ }^{58}$ Sacrifice of segmental arteries in the thoracic spine should be done at the midvertebral body. The risk of left transthoracic unilateral sacrifice of segmental vessels is $0.75 \% .^{64}$ However, bilateral disruption of segmental arteries is not as safe, as shown by the vascular surgery experience with aortic aneurysms. ${ }^{35}$

A clear understanding of the cord location is required prior to thoracic cord decompression. The pedicle ipsilateral to the anterior thoracic approach can be removed to enter the thoracic canal and location of the cord. Anterior instrumentation with screws should be directed away from the spinal cord. The patient should also be in the straight lateral position to ensure the screws are not misdirected into the canal.

Posterior thoracic decompression should be performed similar to cervical spine decompression, with minimal pressure or mobilization of the spinal cord. The Kerrison rongeur should be maintained perpendicular to the bone, and the footplate parallel to the dura mater. Instruments should be held in both hands at all times.

Instrumentation of the posterior thoracic spine with pedicle screws is a relatively safe procedure. In a series of 4604 thoracic pedicle screws, inserted for deformity correction, $0.8 \%$ of patients suffered neurological complications. ${ }^{75}$ Medial pedicle breaches place the spinal cord at risk, especially during deformity correction, in which the cord is typically draped on the concavity of the spine. Preoperative axial CT scan images should be reviewed to assess the diameter of the pedicle isthmus and ensure that the pedicle can be cannulated, and to assess the pedicle trajectory. If the pedicle is too narrow for screw placement, alternative fixation techniques such as an extrapedicular approach to screw placement in the thoracic spine or the use of pedicle hooks should be considered. ${ }^{45}$

Underlying cord diseases such as syringomyelia, tethered cord, or an associated Chiari malformation must be recognized prior to deformity correction. On clinical examination of apparent idiopathic scoliosis patients with neurological signs, patients younger than 11 years of age, with a left thoracic scoliosis, or significant neck or back pain should be further investigated with MR imaging. ${ }^{46}$ Syringomyelia is a risk factor for neurological complications during correction of scoliosis and should be assessed prior to deformity correction.

During coronal or sagittal plane deformity correction, the spinal cord may undergo distraction as the curvature is straightened, leading to disruption of the blood supply to the cord. ${ }^{57}$ Winter $^{86}$ reported on 2031 procedures for scoliosis or kyphosis with no complete SCIs and $0.3 \%$ partial cord injuries. Intraoperative neuromonitoring may detect changes, allowing the surgeon to reverse or decrease the amount of deformity correction. Clear and reliable communication between the surgeon and the neuromonitoring team must exist. An alternative or complement to intraoperative neuromonitoring, is the Stagnara Wake-up test to assess the anterior motor por- 
tion of the spinal cord..$^{39,49,52}$ However, this requires preoperative planning with the aenesthetist and a patient who can understand and comply with directions. The ankleclonus test is another intraoperative test of motor function as described by Hoppenfeld et $a{ }^{43}$ that can be used to test anterior cord function. However, the use of multimodality evoked potential monitoring (MEP and SSEP) combined with continuous and evoked electromyography has largely supplanted the wake-up and ankle clonus tests.

\section{Postoperative Causes of SCI}

Postoperative causes of SCI include epidural hematomas and infection. New postoperative neurological deficits warrant neuroimaging consisting of plain radiographs and MR imaging. Most surgical procedures will cause the development of small and clinically inconsequential epidural hematomas; $; 0,80$ however, those large enough to cause spinal cord compression and warrant surgical intervention are rare, with an incidence of $0.1 \% .^{55}$ Epidural hematomas are typically diagnosed within 24 hours after surgery, although there have been reported cases occurring more than 3 days after surgery. ${ }^{82}$ Risk factors for developing epidural hematomas with spinal cord compression include multilevel decompressions and patients with coagulopathy. ${ }^{51}$ Emergency decompression should be performed within 8 hours as most patients will make good or partial neurological recovery. ${ }^{84}$

Epidural abscesses are also a potential cause of spinal cord compression postoperatively and are very rare. Overall, 1 in 10,000 hospital admissions per year are for epidural abscesses, of which $16 \%$ were due to postoperative infections. ${ }^{4}$ Progression of symptoms include back pain, then radicular pain and weakness, followed by paralysis. Staphylococcus aureus is the most common causative pathogen. Patients may be normothermic and have normal white blood cell counts. ${ }^{13}$ Magnetic resonance imaging with and without $\mathrm{Gd}$ is the imaging modality of choice. Typically, the lesion is isointense with the spinal cord on T1-weighted images and hyperintense on T2weighted images; ${ }^{21} \mathrm{Gd}$ enhances the epidural abscess. Urgent surgical decompression along with antibiotic therapy is warranted if the patient has neurological deficits, if the microorganism is not known, or if the infection is not responding to antibiotic therapy. Epidural abscesses caused by a known organism in patients without deficits can potentially be treated medically. ${ }^{73}$

\section{Long-Term Care of Patients with POSCIs}

The long-term prognosis for patients with POSCIs is variable and can depend on the patient's age, extent of injury, and whether the injury is complete or incomplete. However, based on the cervical myelopathy literature, patients with signal changes on both T1- and T2-weighted images have a worse chance of recovery compared to patients who only have signal changes on T2-weighted images. ${ }^{61,76}$ Serial MR imaging examinations can be performed to assess potential improvement in the cord signal changes.

The surgeon should facilitate appropriate multidisciplinary care for the patient to facilitate optimal long-term recovery and outcome and should also make a commitment to conduct long-term follow-up with the patient. The goals of SCI rehabilitation are to help the patient achieve as much independence as possible through the treatment of all affected systems. The pulmonary system requires careful attention, with frequent mobilization and deep inspirometry to minimize atelectasis and pneumonia. If the cord injury is above C-4, a ventilator or a diaphragmatic stimulator maybe potentially required. The integuments should be carefully assessed, especially the sacral and heel regions. Patients who cannot independently turn in bed need frequent turning every 2 hours and the use of air mattresses to minimize pressure on these regions. Genitourinary care involves teaching the patient to do frequent, intermittent self-catheterizations. Care should be taken to observe for autonomic dysreflexia. Should a hypertensive crisis occur, catheter drainage should be checked in addition to the bowels; 10-mg of nifedipine can be administered during a hypertensive crisis. Bowel training should also be undertaken with stool softeners and suppositories. Counseling and support is required to help the patient adapt psychologically. All of these goals are best reached at specialized SCI rehabilitation centers and typically involve a long-term stay of 3-5 months. Depending on the level of the injury, the degree of patient independence can vary. ${ }^{87}$ Patients with an injury at C-5 or higher cannot achieve functional independence. Patients with an injury at C-6 require occasional assistance with transfers but can use a modified wheelchair. Patients with an injury at C-7 or lower can become completely independent.

\section{Illustrative Case 1: POSCI Prevention Protocol}

This 75-year-old man of Asian descent presented with a progressively worsening gait imbalance and clumsiness in both hands, which had started 1 year prior to his presentation. There was no history of trauma, and he had no bowel or bladder dysfunction. Previously, he was able to ambulate without walking aids, but now required a walker. He had significant worsening of his handwriting ability, difficulty in buttoning his shirts, and repeated episodes of dropping light objects such as coffee cups. In terms of medical history, he had mild, diet-controlled Type 2 diabetes mellitus.

Physical examination revealed that he had lost intrinsic muscle mass in both hands. Assessment of both legs and arms revealed spasticity, with Hoffman and Babinski signs present bilaterally. He had marked clonus in both ankles, and his reflexes were globally hyperreflexic. His gait was extremely unsteady and wide based, despite his use of a walker. His motor strength was grade 4 out of 5 on the Medical Research Council scale. Sensation in both arms and legs was intact to light touch, pin-prick, and proprioception.

Magnetic resonance images revealed severe cervical spinal stenosis extending from C2-3 down to C6-7 from severe spondylosis (Fig. 1). There was an area of signal change within the spinal cord behind C5-6 and C6-7 where the cord was most severely compressed. His cervical spine had maintained a lordotic sagittal alignment. 


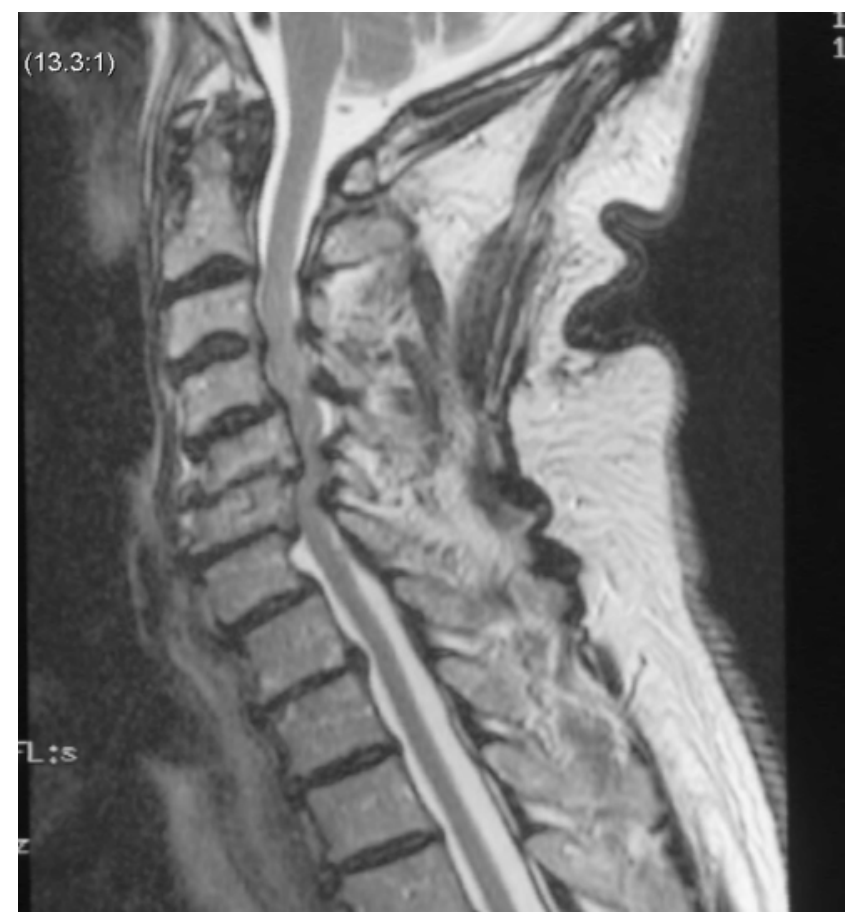

FIG. 1. Case 1. Cervical spine sagittal T2-weighted MR image showing compression of the spinal cord at multiple levels due to severe spondylosis, particularly at C5-6 and C6-7. There is signal change at these two levels.

The patient was admitted to the hospital and gave his consent to undergo posterior cervical decompression and segmental instrumented fusion for his cervical myelopathy from severe spondylosis. The posterior approach was chosen due to the multiple levels of compression. With his sagittal alignment, a posterior decompression would allow the cord to fall posteriorly away from the posterior vertebral body wall and disk bulges.

This surgical procedure had increased risks of SCI. To minimize the potential for injuring his spinal cord and worsening his myelopathy, we implemented the following protocol to reduce the chance of POSCI.

\section{Maintain MABP Above $80 \mathrm{~mm} \mathrm{Hg}$}

Dopamine treatment was initiated prior to anesthesia induction to ensure that his MABP was maintained above $80 \mathrm{~mm} \mathrm{Hg}$. In the setting of underlying spinal cord compression or another pathological entity, which renders the cord at risk for ischemia, we strongly advocate maintenance of spinal cord perfusion through the prevention of hypotension during induction, intraoperatively, and potentially postoperatively. This may require volume resuscitation using crystalloid, maintenance of a normal hematocrit $(>32 \%)$, and vasopressors such as dopamine, followed by levophed if needed. Epinephrine should be avoided as it exerts its effects only on the alpha-receptors, and can reduce spinal cord perfusion. No ideal MABP has been determined. However, previous clinical studies have used an empirical minimum of $80-85 \mathrm{~mm} \mathrm{Hg}$ based on the management of patients with head injuries. ${ }^{83}$

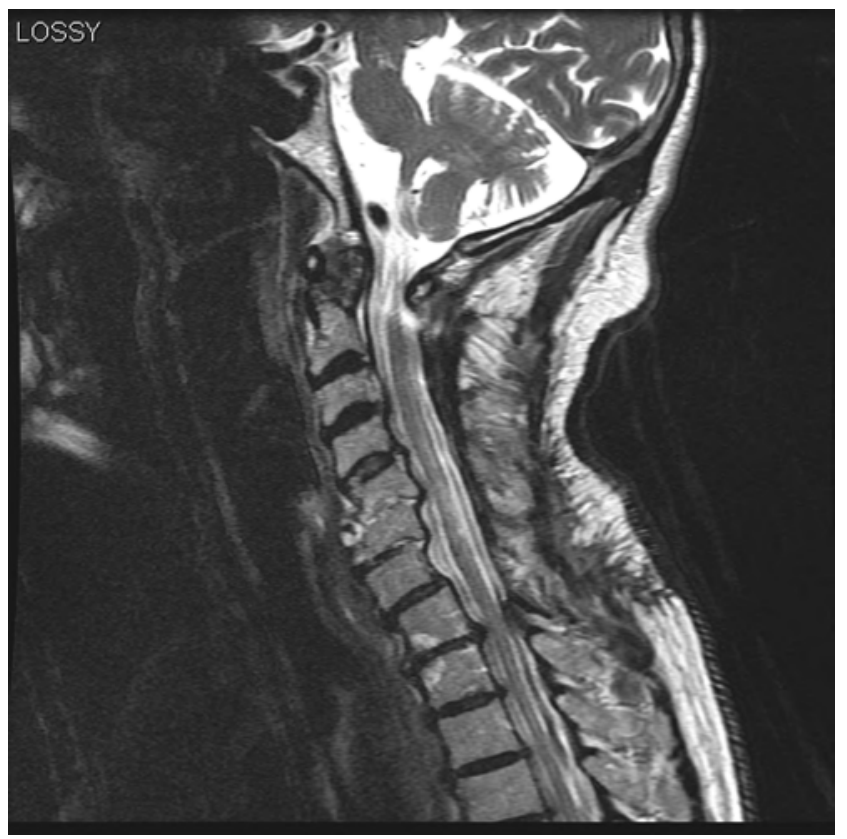

FIG. 2. Case 1. Midline postoperative sagittal T2-weighted MR image showing posterior cervical decompression from $\mathrm{C}-2$ to $\mathrm{C} 7-\mathrm{T} 1$. Residual signal change is present in the spinal cord at C5-6 and C6-7.

\section{Start Treatment With MPSS Preoperatively and Discon- tinue After 24 Hours}

If the spinal cord is at high risk for intraoperative SCI or if work within the spinal cord is going to be done, MPSS can be started before surgery. Naso et al. ${ }^{63}$ showed in their basic science rat model that high-dose MPSS administered prophylactically has a neuroprotective effect by minimizing secondary axonal injury in surgical trauma. The impact of SCI can be devastating, and MPSS offers potential benefits as exhibited in several randomized controlled trials; it also has a relatively safe medication profile. ${ }^{7}$ Based on the recommendations of Bracken et al. ${ }^{8,9}$ (NASCIS II), a $30 \mathrm{mg} / \mathrm{kg}$ bolus of MPSS is given over 15 minutes; this can be done before induction. After a 45 -minute wait, an infusion of $5.4 \mathrm{mg} / \mathrm{kg} / \mathrm{hour}$ is given until the patient is assessed postoperatively. If there is no evidence of SCI, and there is low risk of cord edema from the surgery, steroid treatment can be discontinued. If there is evidence of SCI and/or a moderate-to-high risk of edema in the cord (such as after an intramedullary tumor resection), MPSS can be continued for a total of 24 hours. Because MPSS can cause elevations of blood glucose, potentially predisposing patients to an increased risk of neuronal injury and counteracting the beneficial effects of MPSS, especially in patients with diabetes, blood glucose assessments should be made every 2 hours during infusion of MPSS. ${ }^{33}$ Administration of insulin maybe required to maintain blood glucose within normal limits. In basic science studies, insulin has been shown to be neuroprotective, preventing neuronal cell death. ${ }^{62}$ Our patient, a Type 2 diabetic, received insulin from the anesthetist intraoperatively and an endocrinologist postoperatively to maintain a normal blood sugar profile during MPSS administration. 

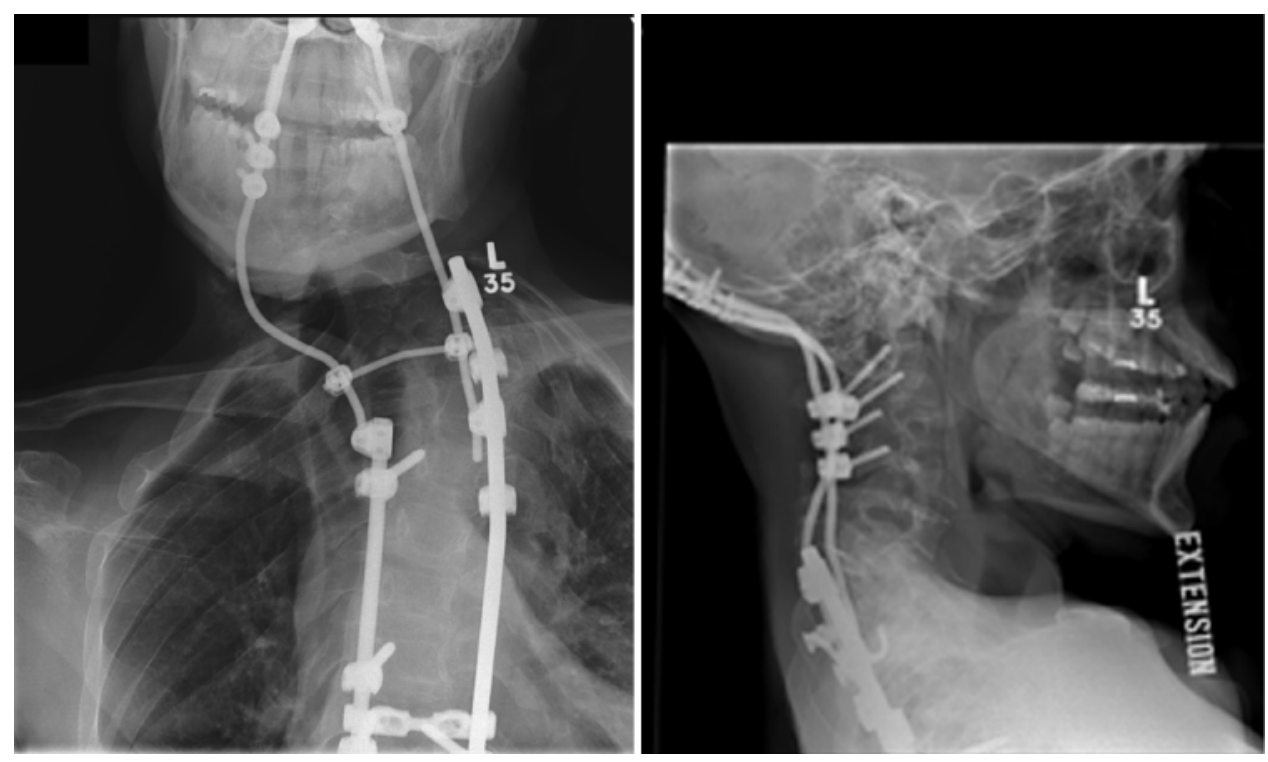

FIG. 3 Case 2. Left: Anteroposterior radiograph showing the broken left cervical rod. The patient has kyphoscoliosis from neurofibromatosis Type 1. Right: Lateral radiograph showing the fractured cervical rod at the cervicothoracic junction.

Although the evidence from the NASCIS trials is controversial, the results show motor improvement when given within 8 hours of the SCI. MPSS administration for acute SCI is supported by numerous basic science studies that have demonstrated the ability of MPSS in deactivating free-radical oxidation products that demyelinate neurons during the secondary cascade following a SCI and reducing edema and inflammation. ${ }^{19,41}$ MPSS is a relatively safe drug as shown by Sauerland et al. ${ }^{67}$ where a systematic review of 51 trials using high dose MPSS versus placebo or nothing showed no evidence of harm for spine surgery. There was no evidence of increased risk for gastrointestinal bleeding, wound complications, pulmonary complications, or death.

\section{Maintain Careful Spine Control}

Fiberoptic intubation was used in our patient to minimize neck extension. The patient was positioned supine on a Jackson table with a Mayfield attachment, and was then turned prone with the rotating frame.

\section{Use Adequate Lighting, Magnification, and Assistance}

\section{Use Multimodal Intraoperative Neuromonitoring}

We used SSEPs, MEPs, and electromyography recordings (for cervical and lumbar procedures). No intraoperative signal changes occurred.

\section{Recognize That Distractive Forces Applied to the Spine May Cause a Combined Stretch/Ischemic Injury}

Distraction, when necessary, should be applied carefully and under neurophysiological monitoring. In our patient, no distraction was required. This protocol is more applicable in deformity correction cases.

\section{Start Decompression Away From the Tightest Stenosis}

Instruments should be held with both hands at all times. A high-speed drill should be used to thin out the compressive osseous structures to an "egg-shell" thickness. Only fine instruments (curettes and thin foot-plate Kerrison punches) should be used for decompression in the cervical and thoracic spine. In our patient, 2 posterior troughs were created at the junction between the lamina and the lateral masses using a Midas bur, followed by removal of the lamina and ligamentum flavum.

\section{Outcome of Protocol}

Utilizing this protocol, we successfully decompressed the cervical spine in our patient with no adverse outcomes (Fig. 2). Six weeks postoperatively, the patient reported improvement in his gait. See Table 1 for an overview of the treatment options outlined here to help minimize the probability of a POSCI from occurring.

\section{Illustrative Case 2: Treatment of POSCI Recognized Postoperatively}

This 33-year-old woman with known cervicothoracic kyphoscoliosis due to neurofibromatosis Type 1, underwent an upper thoracic pedicle subtraction osteotomy with a plan to do a staged anterior cervicothoracic decompression. However, due to a dural tear during the first stage of surgery, the second stage procedure was delayed. While waiting for the second stage surgery, the patient fell and broke her posterior hardware (Fig. 3). She returned to the operating room for revision of the posterior instrumentation to replace the broken rod and gently correct the loss of her original deformity correction.

Awake fiberoptic intubation was performed for both surgeries, and her MABP was maintained over $80 \mathrm{~mm}$ $\mathrm{Hg}$ throughout the operation. Perioperative steroids were not used prior to the first or second operation; MEPs and SSEPs were done during both operations. The Wake-up 


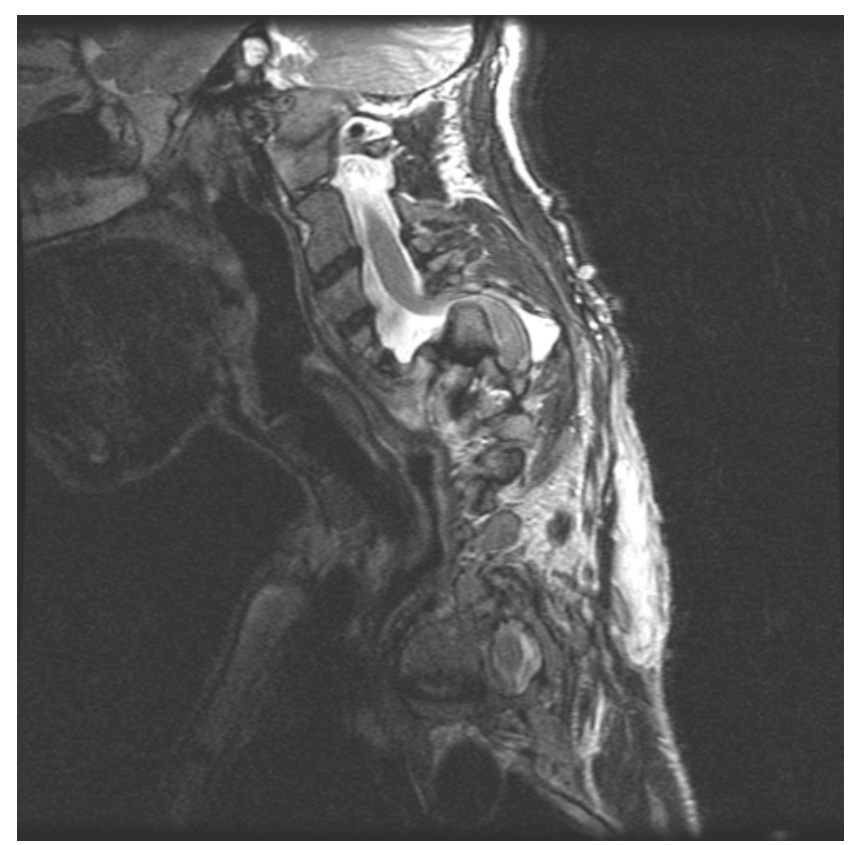

FIG. 4. Case 2. Sagittal T2-weighted MR imaging demonstrating compression of the spinal cord caused by the kyphotic deformity at the cervicothoracic junction.

test was not performed either time. At baseline in the second case, no MEPs could be obtained and the SSEPs were fine. No significant blood loss occurred and the surgical time was 2 hours. When the patient awoke, she had complete paraplegia in both legs, and $\mathrm{C}-7$ paresis on the right, and C-6 paresis on the left due to anterior cord syndrome secondary to deformity correction in the setting of residual ventral compression.

The SCI was immediately recognized, along with its cause from the kyphotic cervicothoracic region causing ongoing residual ventral compression (Fig. 4). She was taken back to the operating room emergently for an anterior cervicothoracic decompression and fusion. Dopamine was administered preoperatively to maintain her MABP above $80 \mathrm{~mm} \mathrm{Hg}$. Methylprednisolone sodium succinate was administered preoperatively under the NASCIS II protocols. An awake fiberoptic intubation was performed. Both MEP and SSEP activity was present in the upper extremities and there were no lower limb MEPs and SSEPs. Following the procedure, some MEP and SSEP activity returned. Postoperative imaging demonstrated excellent decompression (Fig. 5), and she returned to her baseline level of functioning over the next 6 months.

\section{Treatment Options After an Intraoperative SCI}

Similar to the second case example, which highlighted the management of a postoperatively recognized SCI, several steps can be taken to help minimize damage from the secondary cascade following recognition of an intraoperative SCI. First, the occurrence of a SCI must be recognized and acknowledged in order for actions to be taken to reduce the impact of the injury as soon as possible. This involves multimodal neuromonitoring during surgery, and regular and frequent spinal cord neurologic

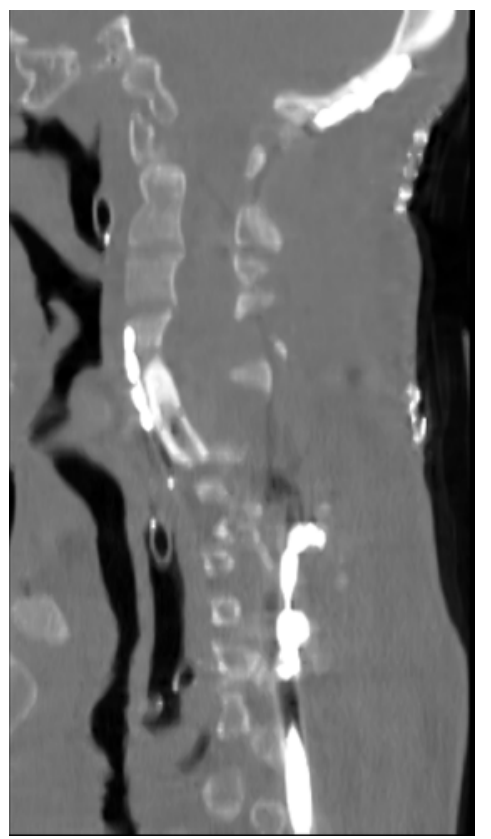

FIG. 5. Case 2. Sagittal CT reconstruction showing decompression of the anterior cervicothoracic junction. A fibular allograft from C-4 to T-2 was used along with an anterior cervical plate.

testing after surgery. If possible, the cause of the intraoperative SCI should be removed such as the instrument or screw or reversal of the deformity correction. Secondly, the MABP should be maintained above $80-85 \mathrm{~mm} \mathrm{Hg}$ and the hematocrit should be corrected. Maintenance of the MABP may require the use of vasopressors such as dopamine and/or levophed. Treatment with MPSS can also be initiated as soon as possible after identification of the SCI. Although meta-analysis data suggest that there are no increases in rates of side effects of MPSS, ${ }^{67}$ a number of other authors have documented potential increases in rates of infections, blood sugar levels, and gastrointestinal bleeding. ${ }^{32,56,60,74}$ Furthermore, the NASCIS trials applied only to blunt, closed SCI and not open spinal cord trauma.

Relative systemic cooling or local cooling can also be performed to minimize oxygen demand from the spinal cord, reducing the potential ischemic damage following a cord injury. However, this is experimental and is not routinely used or offered at most spine surgical centers. The vascular surgery literature for thoracoabdominal aortic aneurysm repairs have shown that cooling the epidural space is potentially neuroprotective and safe..$^{53,77,78}$ The optimal temperature is not known. However, the use of normal saline chilled to $4^{\circ} \mathrm{C}$ to cool the epidural space to $25^{\circ} \mathrm{C}$ has been shown to be effective in minimizing postoperative neurological complications. ${ }^{17}$

If the area operated on is mechanically unstable, the region should be stabilized with screw fixation to create an optimal area for neurological recovery. If cross-links are to be placed for the construct, they should be placed away from the region of injury to minimize scatter and artifact during follow-up CT and MR imaging scans.

Following the completion of surgery, an epidural 
drain can be placed. Cerebrospinal fluid drainage is often used as an adjunct for spinal cord protection following thoracoabdominal aortic aneurysm repair. Coselli et al. ${ }^{12}$ showed in a randomized control trial with and without CSF drainage following thoracoabdominal aortic aneurysm that $2.6 \%$ of patients developed neurologic deficits/ paraplegia with CSF drainage versus $13 \%$ of patients treated without CSF drainage.

The rationale behind CSF drainage is based on animal studies where it was shown that decreasing CSF pressure to $<10 \mathrm{~mm} \mathrm{Hg}$ enhances perfusion of the cord and decreases the risk of ischemic damage. ${ }^{6,38,59}$ Duration of treatment and the actual volume of CSF drainage is not known. However, the risks associated with CSF drainage include meningitis and overdrainage which can result in intraspinal hematomas, subdural/intracerebral hematomas, and acquired foramen magnum stenosis secondary to cerebellar tonsillar herniation. . $^{214,16,68,71,85}$ It is thought that tonsillar herniation occurs due to the pressure difference between the supratentorial and lumbar cistern compartments. ${ }^{72}$ Studies have shown CSF production to be $20 \mathrm{ml} /$ hour. $^{44}$ Because of these risks, it is recommended that CSF drainage be $\sim 15-20 \mathrm{ml} /$ hour and discontinued after 72 hours to minimize infection risk.

\section{Discussion}

Based on our review of the literature, no study has looked at prevention or minimization of the effects of POSCIs. As a result, for this article, treatment options have been developed utilizing evidence from a variety of basic science and clinical studies obtained from a systematic review, both, for prevention and for treatment of recognized POSCIs. As a result, no firm guidelines can be provided and only treatment options are listed. Furthermore, basic science studies may not appropriately translate into clinical practice. Further research would be beneficial in providing better clinical data.

Randomized control trials, considered the gold standard level of evidence, would not be appropriate for the study of POSCIs. It would be challenging to randomize a patient with a POSCI and patient enrollment would be poor. In addition, the number of cases per year would be small, making it impractical to enroll enough patients.

A dedicated study on POSCI can be accomplished through a prospective multicenter cohort study to identify the incidence of POSCI and risk factors that increase the odds of POSCI from occurring and determinants of outcome after POSCI occurs. In addition, the study would provide an overview of what methods are being used to prevent POSCI and what is being done in the event of a POSCI.

Several of the potential treatment options, in the event of a POSCI occurring such as systemic cooling and CSF drainage are controversial and are predominantly found within the literatore on thoracoabdominal aneurysm surgery rather than in the spinal surgical literature. These treatment options warrant further investigation prior to implementation.

\section{Conclusions}

Perioperative SCIs are a risk of surgery around the spinal cord. Multimodal neuromonitoring has been assessed as a method to minimize the chance of POSCI. However, no studies exist that detail how to reduce the impact of a POSCI should it occur. In the present study, we outlined treatment options based on our systematic review of the basic science and clinical literature. Further prospective studies are needed to accurately assess what is being performed in clinical practice to minimize POSCI, identify the incidence of POSCI, and identify factors that determine outcome after POSCI.

\section{Disclaimer}

The authors report no conflict of interest concerning the materials or methods used in this study or the findings specified in this paper.

\section{References}

1. Abumi K, Shono Y, Ito M, et al: Complications of pedicle screw fixation in reconstructive surgery of the cervical spine. Spine 25:962-969, 2000

2. Acikbas SC, Akyuz M, Kazan S, et al: Complications of closed continuous lumbar drainage of cerebrospinal fluid. Acta Neurochir (Wien) 144:475-480, 2002

3. Albert TJ, Klein GR, Joffe D, et al: Use of cervicothoracic junction pedicle screws for reconstruction of complex cervical spine pathology. Spine 23:1596-1599, 1998

4. Baker AS, Ojemann RG, Swartz MN, et al: Spinal epidural abscess. N Engl J Med 293:463-468, 1975

5. Bertalanffy H, Eggert HR: Complications of anterior cervical discectomy without fusion in 450 consecutive patients. Acta Neurochir (Wien) 99:41-50, 1989

6. Bower TC, Murray MJ, Gloviczki P, et al: Effects of thoracic aortic occlusion and cerebrospinal fluid drainage on regional spinal cord blood flow in dogs: correlation with neurologic outcome. J Vasc Surg 9:135-144, 1989

7. Bracken MB: Methylprednisolone and acute spinal cord injury: an update of the randomized evidence. Spine 26 (24 Suppl):S47-S54, 2001

8. Bracken MB, Shepard MJ, Collins WF Jr, et al: Methylprednisolone or naloxone treatment after acute spinal cord injury: 1-year follow-up data. Results of the second National Acute Spinal Cord Injury Study. J Neurosurg 76:23-31, 1992

9. Bracken MB, Shepard MJ, Collins WF, et al: A randomized, controlled trial of methylprednisolone or naloxone in the treatment of acute spinal-cord injury. Results of the Second National Acute Spinal Cord Injury Study. N Engl J Med 322:1405-1411, 1990

10. Bracken MB, Shepard MJ, Hellenbrand KG, et al: Methylprednisolone and neurological function 1 year after spinal cord injury. Results of the National Acute Spinal Cord Injury Study. J Neurosurg 63:704-713, 1985

11. Bracken MB, Shepard MJ, Holford TR, et al: Administration of methylprednisolone for 24 or 48 hours or tirilazad mesylate for 48 hours in the treatment of acute spinal cord injury. Results of the Third National Acute Spinal Cord Injury Randomized Controlled Trial. National Acute Spinal Cord Injury Study. JAMA 277:1597-1604, 1997

12. Coselli JS, Lemaire SA, Koksoy C, et al: Cerebrospinal fluid drainage reduces paraplegia after thoracoabdominal aortic aneurysm repair: results of a randomized clinical trial. J Vasc Surg 35:631-639, 2002

13. Curry WT Jr, Hoh BL, Amin-Hanjani S, et al: Spinal epidu- 


\section{H. Ahn and M. G. Fehlings}

ral abscess: clinical presentation, management, and outcome. Surg Neurol 63:364-371, 2005

14. Dagnew E, van Loveren HR, Tew JM Jr: Acute foramen magnum syndrome caused by an acquired Chiari malformation after lumbar drainage of cerebrospinal fluid: report of three cases. Neurosurgery 51:823-828, 2002

15. Dahlin LB, Rydevik B, McLean WG, et al: Changes in fast axonal transport during experimental nerve compression at low pressures. Exp Neurol 84:29-36, 1984

16. Dardik A, Perler BA, Roseborough GS, et al: Subdural hematoma after thoracoabdominal aortic aneurysm repair: an underreported complication of spinal fluid drainage? J Vasc Surg 36:47-50, 2002

17. Davison JK, Cambria RP, Vierra DJ, et al: Epidural cooling for regional spinal cord hypothermia during thoracoabdominal aneurysm repair. J Vasc Surg 20:304-310, 1994

18. Deen HG, Birch BD, Wharen RE, et al: Lateral mass screwrod fixation of the cervical spine: a prospective clinical series with 1-year follow-up. Spine J 3:489-495, 2003

19. Demopoulos HB, Flamm ES, Seligman ML, et al: Further studies on free-radical pathology in the major central nervous system disorders: effect of very high doses of methylprednisolone on the functional outcome, morphology, and chemistry of experimental spinal cord impact injury. Can J Physiol Pharmacol 60:1415-1424, 1982

20. Dickman CA, Sonntag VK: Posterior C1-C2 transarticular screw fixation for atlantoaxial arthrodesis. Neurosurgery 43:275-280, 1998

21. Djukic S, Lang P, Morris J, et al: The postoperative spine. Magnetic resonance imaging. Orthop Clin North Am 21:603-624, 1990

22. Dommisse GF: The blood supply of the spinal cord. A critical vascular zone in spinal surgery. J Bone Joint Surg Br 56:225-235, 1974

23. Emery SE, Bohlman HH, Bolesta MJ, et al: Anterior cervical decompression and arthrodesis for the treatment of cervical spondylotic myelopathy. Two to seventeen-year follow-up. J Bone Joint Surg Am 80:941-951, 1998

24. Epstein NE, Epstein JA, Carras R, et al: Coexisting cervical and lumbar spinal stenosis: diagnosis and management. Neurosurgery 15:489-496, 1984

25. Faciszewski T, Winter RB, Lonstein JE, et al: The surgical and medical perioperative complications of anterior spinal fusion surgery in the thoracic and lumbar spine in adults. A review of 1223 procedures. Spine 20:1592-1599, 1995

26. Fehlings MG, Tator $\mathrm{CH}$, Linden RD: The relationships among the severity of spinal cord injury, motor and somatosensory evoked potentials and spinal cord blood flow. Electroencephalogr Clin Neurophysiol 74:241-259, 1989

27. Fessler RG, Steck JC, Giovanini MA: Anterior cervical corpectomy for cervical spondylotic myelopathy. Neurosurgery 43:257-265, 1998

28. Fielding JW: Complications of anterior cervical disk removal and fusion. Clin Orthop Relat Res 284:10-13, 1992

29. Flynn TB: Neurologic complications of anterior cervical interbody fusion. Spine 7:536-539, 1982

30. Geisler FH, Coleman WP, Grieco G, et al: The Sygen multicenter acute spinal cord injury study. Spine 26:S87-S98, 2001

31. Geisler FH, Dorsey FC, Coleman WP: Recovery of motor function after spinal-cord injury-a randomized, placebocontrolled trial with GM-1 ganglioside. N Engl J Med 324:1829-1838, 1991

32. Gerndt SJ, Rodriguez JL, Pawlik JW, et al: Consequences of high-dose steroid therapy for acute spinal cord injury. J Trauma 42:279-284, 1997

33. Gisselsson L, Smith ML, Siesjo BK: Hyperglycemia and focal brain ischemia. J Cereb Blood Flow Metab 19:288-297, 1999
34. Gore DR, Sepic SB: Anterior cervical fusion for degenerated or protruded discs. A review of one hundred forty-six patients. Spine 9:667-671, 1984

35. Grabitz K, Sandmann W, Stuhmeier K, et al: The risk of ischemic spinal cord injury in patients undergoing graft replacement for thoracoabdominal aortic aneurysms. J Vasc Surg 23:230-240, 1996

36. Graham AW, Swank ML, Kinard RE, et al: Posterior cervical arthrodesis and stabilization with a lateral mass plate. Clinical and computed tomographic evaluation of lateral mass screw placement and associated complications. Spine 21:323-328, 1996

37. Graham JJ: Complications of cervical spine surgery. A fiveyear report on a survey of the membership of the Cervical Spine Research Society by the Morbidity and Mortality Committee. Spine 14:1046-1050, 1989

38. Griffiths IR, Pitts LH, Crawford RA, et al: Spinal cord compression and blood flow. I. The effect of raised cerebrospinal fluid pressure on spinal cord blood flow. Neurology 28:11451151, 1978

39. Gunnarsson T, Krassioukov AV, Sarjeant R, et al: Real-time continuous intraoperative electromyographic and somatosensory evoked potential recordings in spinal surgery: correlation of clinical and electrophysiologic findings in a prospective, consecutive series of 213 cases. Spine 29:677-684, 2004

40. Haid RW Jr, Subach BR, McLaughlin MR, et al: C1-C2 transarticular screw fixation for atlantoaxial instability: a 6-year experience. Neurosurgery 49:65-68, 2001

41. Hall ED: Neuroprotective actions of glucocorticoid and nonglucocorticoid steroids in acute neuronal injury. Cell Mol Neurobiol 13:415-432, 1993

42. Harms J, Melcher RP: Posterior C1-C2 fusion with polyaxial screw and rod fixation. Spine 26:2467-2471, 2001

43. Hoppenfeld S, Gross A, Andrews C, et al: The ankle clonus test for assessment of the integrity of the spinal cord during operations for scoliosis. J Bone Joint Surg Am 79:208-212, 1997

44. Huang TY, Chung HW, Chen MY, et al: Supratentorial cerebrospinal fluid production rate in healthy adults: quantification with two-dimensional cine phase-contrast MR imaging with high temporal and spatial resolution. Radiology 233:603-608, 2004

45. Husted DS, Yue JJ, Fairchild TA, et al: An extrapedicular approach to the placement of screws in the thoracic spine: an anatomic and radiographic assessment. Spine 28:2324-2330, 2003

46. Inoue M, Minami S, Nakata Y, et al: Preoperative MRI analysis of patients with idiopathic scoliosis: a prospective study. Spine 30:108-114, 2005

47. Kobrine AI, Doyle TF, Rizzoli HV: Spinal cord blood flow as affected by changes in systemic arterial blood pressure. J Neurosurg 44:12-15, 1976

48. Kobrine AI, Evans DE, Rizzoli HV: The effects of ischemia on long-tract neural conduction in the spinal cord. J Neurosurg 50:639-644, 1979

49. Koscielniak-Nielsen ZJ, Stens-Pedersen HL, Hesselbjerg L: Midazolam-flumazenil versus propofol anaesthesia for scoliosis surgery with wake-up tests. Acta Anaesthesiol Scand 42:111-116, 1998

50. Kotilainen E, Alanen A, Erkintalo M, et al: Postoperative hematomas after successful lumbar microdiscectomy or percutaneous nucleotomy: a magnetic resonance imaging study. Surg Neurol 41:98-105, 1994

51. Kou J, Fischgrund J, Biddinger A, et al: Risk factors for spinal epidural hematoma after spinal surgery. Spine 27:1670-1673, 2002

52. Krassioukov AV, Sarjeant R, Arkia H, et al: Multimodality intraoperative monitoring during complex lumbosacral procedures: indications, techniques, and long-term follow-up re- 
view of 61 consecutive cases. J Neurosurg Spine 1:243-253, 2004

53. Kwon BK, Mann C, Sohn, HM, Hilibrand AS, Phillips FM, Wang JC et al: Hypothermia for spinal cord injury. Spine $\mathbf{J}$ [epub ahead of print], 2008

54. Laroche M, Moulinier L, Arlet J, et al: Lumbar and cervical stenosis. Frequency of the association, role of the ankylosing hyperostosis. Clin Rheumatol 11:533-535, 1992

55. Lawton MT, Porter RW, Heiserman JE, et al: Surgical management of spinal epidural hematoma: relationship between surgical timing and neurological outcome. J Neurosurg 83:1-7, 1995

56. Lee HC, Cho DY, Lee WY, et al: Pitfalls in treatment of acute cervical spinal cord injury using high-dose methylprednisolone: a retrospect audit of 111 patients. Surg Neurol 68 (1 Suppl):S37-S42, 2007

57. MacEwen GD, Bunnell WP, Sriram K: Acute neurological complications in the treatment of scoliosis. A report of the Scoliosis Research Society. J Bone Joint Surg Am 57:404408, 1975

58. Maliszewski M, Ladzinski P, Aleksandrowicz R, et al: Occlusion of radicular arteries - reasons, consequences and anastomotic substitution pathways. Spinal Cord 37:710-716, 1999

59. Miyamoto K, Ueno A, Wada T, et al: A new and simple method of preventing spinal cord damage following temporary occlusion of the thoracic aorta by draining the cerebrospinal fluid. J Cardiovasc Surg (Torino) 1:188-197, 1960

60. Molano Mdel R, Broton JG, Bean JA, et al: Complications associated with the prophylactic use of methylprednisolone during surgical stabilization after spinal cord injury. J Neurosurg 96:267-272, 2002

61. Morio Y, Teshima R, Nagashima H, et al: Correlation between operative outcomes of cervical compression myelopathy and mri of the spinal cord. Spine 26:1238-1245, 2001

62. Nakao Y, Otani H, Yamamura T, et al: Insulin-like growth factor 1 prevents neuronal cell death and paraplegia in the rabbit model of spinal cord ischemia. J Thorac Cardiovasc Surg 122:136-143, 2001

63. Naso WB, Perot PL Jr, Cox RD: The neuroprotective effect of high-dose methylprednisolone in rat spinal cord hemisection. Neurosci Lett 189:176-178, 1995

64. Orchowski J, Bridwell KH, Lenke LG: Neurological deficit from a purely vascular etiology after unilateral vessel ligation during anterior thoracolumbar fusion of the spine. Spine 30:406-410, 2005

65. Petitjean ME, Pointillart V, Dix merias F, et al: [Medical treatment of spinal cord injury in the acute stage.] Ann Fr Anesth Reanim 17:114-122, 1998 (Fr)

66. Rydevik B, Lundborg G: Permeability of intraneural microvessels and perineurium following acute, graded experimental nerve compression. Scand J Plast Reconstr Surg 11:179187,1977

67. Sauerland S, Nagelschmidt M, Mallmann P, et al: Risks and benefits of preoperative high dose methylprednisolone in surgical patients: a systematic review. Drug Saf 23:449-461, 2000

68. Schade RP, Schinkel J, Visser LG, et al: Bacterial meningitis caused by the use of ventricular or lumbar cerebrospinal fluid catheters. J Neurosurg 102:229-234, 2005

69. Sekhon LH, Fehlings MG: Epidemiology, demographics, and pathophysiology of acute spinal cord injury. Spine 26:S2S12, 2001

70. Senter HJ, Venes JL: Loss of autoregulation and posttraumatic ischemia following experimental spinal cord trauma. J Neurosurg 50:198-206, 1979
71. Settepani F, van Dongen EP, Schepens MA, et al: Intracerebellar hematoma following thoracoabdominal aortic repair: an unreported complication of cerebrospinal fluid drainage. Eur J Cardiothorac Surg 24:659-661, 2003

72. Snow RB, Kuhel W, Martin SB: Prolonged lumbar spinal drainage after the resection of tumors of the skull base: a cautionary note. Neurosurgery 28:880-882, 1991

73. Sorensen P: Spinal epidural abscesses: conservative treatment for selected subgroups of patients. Br J Neurosurg 17:513518,2003

74. Suberviola B, Gonzalez-Castro A, Llorca J, et al: Early complications of high-dose methylprednisolone in acute spinal cord injury patients. Injury 39:748-752, 2008

75. Suk SI, Kim WJ, Lee SM, et al: Thoracic pedicle screw fixation in spinal deformities: are they really safe? Spine 26:2049-2057, 2001

76. Suri A, Chabbra RP, Mehta VS, et al: Effect of intramedullary signal changes on the surgical outcome of patients with cervical spondylotic myelopathy. Spine J 3:33-45, 2003

77. Tabayashi K, Motoyoshi N, Akimoto H, et al: Epidural cooling for regional spinal cord hypothermia during most or all of descending thoracic or thoracoabdominal aneurysm repair. Acta Chir Belg 102:224-229, 2002

78. Tabayashi K, Tabayashi K: Spinal cord protection during thoracoabdominal aneurysm repair. Surg Today 35:1-6, 2005

79. Tator CH, Fehlings MG: Review of the secondary injury theory of acute spinal cord trauma with emphasis on vascular mechanisms. J Neurosurg 75:15-26, 1991

80. Teplick JG, Haskin ME: Review. Computed tomography of the postoperative lumbar spine. AJR Am J Roentgenol 141:865-884, 1983

81. Tew JM Jr, Mayfield FH: Complications of surgery of the anterior cervical spine. Clin Neurosurg 23:424-434, 1976 PubMed

82. Uribe J, Moza K, Jimenez O, et al: Delayed postoperative spinal epidural hematomas. Spine J 3:125-129, 2003

83. Vale FL, Burns J, Jackson AB, et al: Combined medical and surgical treatment after acute spinal cord injury: results of a prospective pilot study to assess the merits of aggressive medical resuscitation and blood pressure management. J Neurosurg 87:239-246, 1997

84. Vandermeulen EP, Van AH, Vermylen J: Anticoagulants and spinal-epidural anesthesia. Anesth Analg 79:1165-1177, 1994

85. Weaver KD, Wiseman DB, Farber M, et al: Complications of lumbar drainage after thoracoabdominal aortic aneurysm repair. J Vasc Surg 34:623-627, 2001

86. Winter RB: Neurologic safety in spinal deformity surgery. Spine 22:1527-1533, 1997

87. Woolsey RM: Rehabilitation outcome following spinal cord injury. Arch Neurol 42:116-119, 1985

88. Young W, DeCrescito V, Tomasula JJ, et al: The role of the sympathetic nervous system in pressor responses induced by spinal injury. J Neurosurg 52:473-481, 1980

Manuscript submitted July 15, 2008.

Accepted October 1, 2008.

Address correspondence to: Michael Fehlings, M.D., Ph.D., F.R.C.S.C., University of Toronto Spine Program, 399 Bathurst St., 4WW-449, Toronto, Ontario, Canada M5T 2S8. 